\title{
A CULTURA PARTICIPATIVA E AS PRÁTICAS DE LETRAMENTOS DE FÃS DE FICÇÃO: UMA INVESTIGAÇÃO EMPÍRICA
}

\author{
CULTURA DE LA PARTICIPACIÓN Y LAS PRÁCTICAS DE LAS NUEVAS \\ ALFABETIZACIONES DIGITALES DE LOS FANS: UNA INVESTIGACIÓN \\ EMPÍRICA
}

\author{
PARTICIPATORY CULTURE AND FANFICTION PRACTICES OF \\ LITERACIES: AN EMPIRICAL APPROACH
}

Bianca Jussara Borges CLEMENTE ${ }^{1}$

Resumo: Neste artigo apresento uma investigação empírica com abordagem de estudo exploratório com elementos da etnografia virtual sobre a cultura participativa e às práticas de letramentos digitais de fãs de ficção, para tanto, utilizei da observação participante e registro de diário de pesquisadora para a coleta de dados sobre as interações dos fãs de ficção em um grupo de rede social online e um site nacional especializado em narrativas de fãs de ficção (fanfiction). $\mathrm{O}$ objetivo desta investigação empírica foi identificar como a cultura participativa se estabelece nas práticas de letramentos digitais dos fãs de ficção nesses espaços virtuais. Para nortear a observação participante da investigadora foram apontadas algumas questões de pesquisa: 1) Como a cultura participativa influencia às práticas de letramentos digitais dos fãs de ficção nos espaços virtuais? 2) Quais são as motivações dos fãs de ficção para elaborarem suas fanfictions? A interpretação dos dados coletados estará em diálogo com o arcabouço teórico que abarca à cultura participativa e os letramentos digitais e, caminha para além das fronteiras disciplinares ao dialogar com a Linguística Aplicada (IN) disciplinar que possibilita uma análise às práticas discursivas e sociais em espaços virtuais.

Palavras-chave: Cultura Participativa. Letramentos Digitais. Fanfiction.

RESUMEN: En este artículo presento una investigación empírica con el enfoque de estudio exploratorio con elementos de la etnografía virtual en la cultura participativa y alfabetizaciones digitales las prácticas de los fans de ficción, siendo así, hizo uso de la observación participante y el investigador él escribió en el diario para la colección los datos de la investigación en las interacciones de los fans de ficción en un grupo de Web 2.0 social en línea y un sitio web nacional especializada en los fans de ficción (fanfiction). El objetivo de esta investigación empírica fue identificar cómo la cultura participativa se establece en las alfabetizaciones digitales en prácticas de los fans de ficción en estos espacios virtuales. Para guiar la observación participante el investigador se identificaron algunas preguntas de investigación: 1) ¿Cómo influye la cultura participativa las alfabetizaciones digitales prácticas de los fans de ficción en

${ }^{1}$ Doutoranda em Interdisciplinar de Linguística Aplicada. UFRJ - Universidade Federal do Rio de Janeiro. Faculdade de Letras - Programa Interdisciplinar de Pós-graduação em Linguística Aplicada. Rio de Janeiro - RJ - Brasil. Pesquisadora Associada do Laboratório de Tecnologias da Informação e da Comunicação, LATEC/UFRJ - biancaclemente2005@yahoo.com.br

RIAEE - Revista Ibero-Americana de Estudos em Educação, v. 11, n. esp. 3, p.1710-1726, 2016 
los espacios virtuales? 2) ¿Cuáles son las motivaciones de los fans de ficción para desarrollar su fanfiction? La interpretación de los datos recogidos estará en diálogo con el marco teórico conceptual que abarca la cultura participativa y alfabetizaciones digitales y va más allá de las fronteras disciplinarias para dialogar con la lingüística aplicada que permite un análisis de las prácticas discursivas y sociales en los espacios virtuales.

PALABRAS CLAVE: Cultura Participativa. Alfabetizaciones digitales. Fanfiction.

ABSTRACT: This article presents an empirical investigation with exploratory studies approach and some elements of virtual ethnography about participatory culture and digital literacies practices fanfictions. Therefore, made use of participative observation and researcher of daily record for the collection research data about the interactions of fanfictions in an online social network group and a national website specializing in narrative of fanfictions. The aim of this empirical research was to identify how participatory culture established in the digital literacies practices of fanfictions in these virtual environments. To guide the participative observation the researcher were identified some research questions: 1) How participatory culture influences the digital literacies practices of fiction fans in the virtual spaces? 2) What are the motivations of fanfictions to develop their narratives? The interpretation of the data collected will be in dialogue with the theoretical framework that involves the participatory culture and digital literacies and goes beyond disciplinary boundaries to dialogue with Applied Linguistics (IN) discipline that enables an analysis of the discursive and social practices in virtual environment.

KEYWORDS: Participatory Culture. Digital literacies. Fanfiction.

\section{Introdução}

A cibercultura abarca redes comunicacionais que se compõem nas interações socioculturais e por meio dos conteúdos digitais produzidos nas redes sociais online, como também, nos múltiplos espaços virtuais. Nessas teias há a tessitura de novas vertentes sobre a cultura digital na modernidade. Nesses espaços virtuais e de cultura digital surgem gêneros híbridos e gêneros digitais, tal como o gênero digital chamado fanfiction - narrativas ficcionais elaboradas por fãs de ficção, que se fortaleceu enquanto gênero digital a partir do advento da Web 2.0. A Cultura Participativa compõe um legado das práticas de letramentos dos fãs de ficção nas redes sociais online e nos sites especializados em narrativas e performances de fãs de ficção. Nesse contexto, a Web 2.0 proporcionou maior interatividade, comunicabilidade e compartilhamento, 
além de elencar os comentários, apreciações e críticas dos usuários em espaço virtuais. Neste artigo apresentamos o termo Cultura Participativa em diálogo com os construtos teóricos de Henry Jenkins (2009) e Janet Murray (2003) sobre como esses teóricos estabelecem o diálogo sobre o que é a cultura digital nos espaços virtuais online e como são construídas as percepções de cultura participativa, ativa e em rede. Como também, como as práticas discursivas e sociais constituem as práticas de letramentos dos fãs de ficção a partir dos construtos da Linguística Aplicada (IN) disciplinar de Moita Lopes (2006).

A abordagem de cultura digital está em pleno auge sob novas teorizações, pesquisas e levantamentos, sendo assim, em redes sociais online está em movimento de contextualização e recontextualização, já que os sujeitos sociais em redes online estão criando, elaborando e compartilhando de formas múltiplas e multifacetadas as próprias experiências e manifestações culturais como e-poesia, batalhas de narrativas digitais, Mashups e vídeos dos mais simples aos mais elaborados processos midiáticos. Para tanto, nesses processos de elaboração individual ou coletiva, também estão inseridos os gêneros digitais, tais como o fanfiction. Essas narrativas ficcionais digitais elaboradas por fãs de ficção são inspiradas a partir da nostalgia causada por um determinado cânone da indústria cultural massiva (livros, séries, filmes, músicas), dessa forma, os consumidores culturais denominados como prosumer $^{2}$ começam a elaborar, revigorar e compartilhar motes ficcionais. Entre muitas controvérsias sobre a própria intelectual da obra original, o cânone, e, as narrativas ficcionais digitais elaboradas por fãs de ficção, muitos fãs de ficção já iniciam suas próprias narrativas ficcionais digitais evidenciando que apenas pegaram por empréstimo determinado personagem/cenário/enredo/mote ficcional da obra referenciada, fonte de inspiração (CLEMENTE, 2013; JENKINS, 2009; MURRAY, 2003; VARGAS; 2005).

Os participantes dessa investigação têm faixa etária diversas, muitos são estudantes do ensino básico ao ensino superior. As identidades de gênero também são múltiplas de acordo com a contemporaneidade. O que os aproxima são as narrativas ficcionais originais e as narrativas feitas por fãs de ficção. Os sujeitos sociais que elaboram essas narrativas digitais são chamados de (ficwrites/escritores fãs de ficção) e

\footnotetext{
${ }^{2}$ Prosumer é um termo utilizado por Henry Jenkins para designar o ato do consumidor de cultura de massa como produtor de derivados dessa cultura, como por exemplo, vídeos clipes de paródia de uma música original. O termo Prosumer foi mencionado pela primeira vez em 1980 por Alvin Toffler no livro The Third Wave.
} 
o público-alvo são chamados de (ficreaders/ leitores fãs de ficção) sendo assim buscamos compreender o gênero digital fanfiction a partir da interação entre os sujeitos sociais que participam e interagem nos espaços virtuais.

\section{Método}

Essa investigação é empírica combinada com estudo exploratório, além de termos utilizado instrumentos de coleta de dados que estão alinhados com a vertente da etnografia virtual de Hine (2000), já que os sujeitos sociais estão online e interagem em espaços virtuais. Ao longo deste estudo exploratório foram levantadas algumas pesquisas, como a de Vargas (2005), Clemente (2013) e de Clemente \& Haguenauer (2014) que apontam para o tema dos fanfictions como sendo esses gêneros digitais emergentes resultantes das práticas de letramentos digitais dos fãs de ficção nas redes sociais online. Para tanto, também foi utilizado a observação participante online, como ainda, registros do diário da pesquisadora. Esses instrumentos de, o diário, teve por finalidade a anotação das interações que remetiam à conduta regimental dos fãs de ficção no site especializado Nyah! Fanfiction (https://fanfiction.com.br/) e como esses sujeitos sociais online estabeleciam suas interações nos comentários, críticas, sugestões e compartilhamentos de conteúdo.

O conjunto metodológico combinado nesta investigação visa compreender a partir das questões norteadoras como procedem a elaboração das narrativas digitais dos fãs de ficção em alinhamento à nostalgia de poder continuar movente a essência da obra original em outros contextos elaborados pelos fãs de ficção, seja em discussões em redes sociais online ou em plataformas online como blogs de fandoms - são reinos do universo dos fãs de ficção e faz referência aos grupos de um determinado livro, filme ou personagem de obra original. Nesse ínterim, muitos leitores/fãs de ficção passam a escritores/fãs de ficção. Nesse contexto de modernidade líquida Bauman (2001) há muita curiosidade e busca por parte dos escritores/fãs de ficção por elementos ficcionais que possam manter a essência da obra original, para tanto, interagem continuamente nos grupos de fãs de ficção na rede social online Facebook. 


\section{Resultados}

$\mathrm{Na}$ primeira etapa desta investigação fizemos um estudo exploratório que compreendeu os espaços virtuais como grupo virtual na rede social online, Facebook, além de acompanhar e mapear os espaços de interação de do site especializado, o Nyah! Fanfiction (www.fanfiction.com.br). Os instrumentos de coleta de dados utilizados nesse estudo exploratório têm inspiração na etnografia virtual da Hine (2000) em que a pesquisadora tomou a postura de observadora participante como membro da comunidade virtual online no Facebook e, num cadastro de perfil no site especializado no gênero digital fanfiction.

Durante a observação participante e os registros no diário sobre as interações dos fãs de ficção nos espaços virtuais, algumas evidências foram encontradas e começaram a responder as questões norteadoras para essa investigação empírica.

Nessa investigação a observação participante se deu em um site especializado em narrativas de fã de ficção - fanfiction e, em um grupo virtual de fãs de ficção na rede social online Facebook. Os participantes dessa investigação são sujeitos sociais de faixas etárias múltiplas e o enquadre de identidade de gênero múltiplas, no âmbito profissional exercem desde a ocupação de estudantes da educação básica e superior, quanto já são profissionais estabelecidos em diversas áreas do conhecimento. Contudo, nos relatos dos comentários a paixão pelas narrativas ficcionais são o que os aproximam nos espaços virtuais.

No estudo exploratório auxiliou-nos ao entendimento da usabilidade do site especializado em narrativas digitais e, no grupo virtual o estudo exploratório norteou a compreensão sobre como os pares interagem e compartilham narrativas digitais de fãs de ficção. No site Nyah!Fanfiction, os sujeitos sociais fãs de ficção estão comprometidos com um determinado conteúdo, ou seja, as narrativas estão classificadas e dividas em categorias. Dessa forma, as narrativas digitais são elaboradas a partir de um universo ficcional derivado das confluências, convergências e divergências entre a obra original de audiência massiva e o contínuo pensado pelos fãs de ficção.

Ao selecionar um site nacional em língua portuguesa, o Nyah!Fanfiction (www.fanfiction.com.br) foram considerados alguns itens como a apresentação visual do site, uma análise dos recursos disponibilizados, ferramentas de navegação e interatividade do usuário com o site. Isso posto, devido à organização e visibilidade 
atribuída pelos próprios fãs de ficção no grupo virtual nas redes sociais online do Facebook.

Cabe ressaltar que, enquanto pesquisadora observadora participante no campo virtual online, estabelecemos a interação com um grupo virtual por meio da rede social online Facebook, o perfil pessoal detalhado da pesquisadora foi mantido da mesma forma como foi pedido autorização para utilizar o conteúdo de interação da comunidade para análise de cunho acadêmico, todavia, estabeleceu-se a preservação do nome da comunidade virtual quanto das identidades dos membros desta comunidade virtual. Todo o processo foi acompanhado pela moderação do grupo virtual e dos administradores.

Na rede social online Facebook, o grupo virtual interage entre imagens atrativas e, às vezes polemicas para ganhar atenção da audiência, sendo assim, os comentários e debates mais críticos sobre os motes ficcionais dos fandons ou sobre a os fatos do cotidiano são acompanhados de perto pelos administradores/moderadores do grupo virtual. Muitas interações são aleatórias e com bases pessoais e, em sua maioria de base coletiva que avançam informação e conteúdo para além dos assuntos do grupo virtual. No estudo exploratório conseguimos identificar as regras de conduta, os valores e conceitos estabelecidos coletivamente para que haja melhor aproveitamento do espaço virtual e da liberdade de expressão sem agressão.

A primeira questão norteadora é: como a cultura participativa influencia às práticas de letramentos dos fãs de ficção nos espaços virtuais? Nos registros da observação participante, os pontos de interesse são sobre como os fãs de ficção lidam com a nostalgia após o final de uma trama literária, essa nostalgia do fã de ficção começa a ser suprida pelas interações na rede social online Facebook, já que nas interações nessa rede social muitos fãs de ficção postam imagens, histórias motivacionais e os links das fanfiction que falam sobre o mote ficcional. Desta forma, o enredo pode continuar movente entre os leitores fãs de ficção, seja em discussões em redes sociais online, seja nos comentários nos espaços virtuais como os sites especializados em narrativas digitais. Nesse contexto de modernidade líquida Bauman (2001) há muita curiosidade e busca, por parte dos escritores fãs de ficção, por elementos ficcionais que possam manter a essência da obra original.

De acordo com o registrado no diário da pesquisadora, no grupo virtual da rede social online Facebook, o papel do administrador não fica resumido as ações de adicionar ou excluir membros, ou seja, essa função requer a mediação das discussões ou 
comentários mais acirrados sobre um determinado assunto. A mediação dessas redes sociais online são feitas por fãs de ficção designados como administradores do grupo e moderadores nesses espaços virtuais, sendo assim, esses espaços virtuais são dinâmicos e a informação circula com fluidez, porque esses fãs de ficção estão sempre estabelecendo novas redes de informação e são muito disponíveis a colaboração, interação, revisão, sugestão de material, não obstante, esses espaços também são sobretudo, espaços de debate e de posicionamento crítico, visam a defesa de direitos autorais, porque entendem que fanfiction é uma narrativa sobre um mote ficcional de interesse do fã de ficção e está distante de violação dos diretos autorais e/ou plágio, porque não é admitido dentro do fandom quem copie narrativas iguais aos autores originais.

De acordo com a observação registrada no diário da pesquisadora foi a noção de plágio dentro do fandom é quando algum fã de ficção se apropria da narrativa de outrem, isto é estabelecido em regras e conduta como falta gravíssima, passivo de ser expulso dos espaços de compartilhamento de narrativas. Sendo assim, os espaços virtuais compartilhados por fãs de ficção são espaços de criticidade e ativismo social, algo marcante na Cultura Participativa e na Cultura Digital.

A segunda questão norteadora é: quais são as motivações dos fãs de ficção para elaborarem suas fanfictions? Ao longo da observação participante e dos registros no diário de investigação constatou-se que a narrativa de ficção de fã (fanfiction) são elaboradas para proporcionar muito mais do que continuidade, isso porque são planejadas para contribuir para o imaginário atribuído ao cânone original de inspiração. Clemente (2013) e Clemente e Haguenauer (2014) ressaltam que essa contribuição aproxima à relação do fã de ficção com as obras literárias, todavia, os escritores fãs de ficção ao ampliarem suas próprias experiências de consumo cultural, também, estão contribuindo para a consolidação de um novo gênero discursivo, podendo também ser considerado como gênero emergente em contexto digital de acordo com o construto teórico de Marcuschi e Xavier (2004). Sobretudo, este novo gênero discursivo estabelece uma nova relação de práticas discursivas e de práticas sociais em espaços virtuais. Portanto, esse formato de novas narrativas ficcionais propõe não somente continuidade à narrativa original, mas agrega novas atribuições aos personagens e desdobramentos alternativos, criando assim, novos fandom (reinos) no universo ficcional. 
Essas novas narrativas ficcionais digitais movimentam o grupo virtual em processo contínuo de inferências, comentários, discussões, polêmicas, elogios e recomendações entre os leitores fãs de ficção e escritores fãs de ficção imersos no universo ficcional.

$\mathrm{Na}$ fase do estudo exploratório sobre a usabilidade do site especializado, o Nyah!Fanfiction, verificamos que há muitas categorias para designar o conteúdo especifico da fanfiction elaborada, como também, existem distinções entre o que seja uma fanfiction e o que são narrativas originais feitas por escritores fãs de ficção. Portanto, a distinção mais simples entre esses dois gêneros digitais está situada na perspectiva de criação, enquanto no fanfiction a narrativa está atrelada a um fandom em colaboração ao mote ficcional de inspiração, para designar narrativas originais, essas precisam ser independentes de qualquer fandom e, ainda, são elaboradas a partir do imaginário do próprio escritor.

Essas narrativas também são adicionadas aos favoritos no site, compartilhados em comentários nas redes sociais online e, assim proporcionam uma nova experiência de cultura digital em que o consumo não é o protagonista, porém a produção independente está em crescimento. De fato, são gerações que leem o que elaboram, o que compartilham e refazem os próprios percursos narrativos ao considerar os comentários do fandom, do reader beta ${ }^{3}$.

O mesmo acontece nas explicações sobre como as narrativas textuais estão se transmutando para as telas sendo organizadas, elaboradas e consumidas no contexto da modernidade líquida. Os fãs de ficção que se identificam enquanto escritores elaboram suas fanfictions para um fandom exigente seja pela originalidade da narrativa escrita, pelos elementos combinados na mesma ou pelos finais almejados pelo fandom. Em qualquer movimento na grande rede (Internet) as narrativas digitais libertam-se da materialidade para assumirem formas virtuais mais dinâmicas, plásticas e maleáveis (MARCUSCHI, 2004).

O site foi criado para divulgar e reunir os fãs de fandons (reinos) variados, além de proporcionar o entretenimento por meio da leitura e, também, incentivar a escrita criativa. Esse site é gratuito, contudo, há regras de convivência, de conduta e de condução aos direitos autorais.

\footnotetext{
${ }^{3} \mathrm{O}$ termo beta reader refere-se aos revisores textuais voluntários ou não dentro das comunidades virtuais. Dentro dessas comunidades virtuais e nos sites especializados em narrativas digitais, eles oferecem e mantem suporte de dicas e aulas sobre a gramática da língua portuguesa.
} 
O acesso ao site é feito por cadastro gratuito, sendo assim, os escritores fãs de ficção precisam adquirir uma conta. Os usuários online também podem ter uma conta, mas isso não implica acessar o site para leituras e busca de informação sobre qualquer história postada nesse ambiente virtual. Há uma preocupação por parte dos moderadores e administradores do site sobre a coautoria de histórias de ficção; a questão dos leitores fãs de ficção mais experientes (beta reader) em relação ao plágio entre os próprios escritores fãs de ficção ou cópia abusiva da obra original.

No diário da pesquisadora foi registado que a interação dialógica é estabelecida não somente quando leitores fã de ficção deixam comentários criteriosos no espaço online do escritor fã de ficção, há outras formas de interação e alteridade, tais como, a representatividade do leitor beta reader (revisor de texto) que é solicitado para a ajudar um escritor fã de ficção a elaborar melhor a escrita, a revisar a gramática e sugerir adequações as narrativas. Segundo Clemente (2013: p.67-68) explicita a presença do beta reader e ação de revisor "[...] o termo betagem característico dos produtos tecnológicos ainda em processo de testagem e aperfeiçoamento. O leitor beta é escolhido pela experiência pela escrita de fanfiction, leitura e comentários [...]" a interação e alteridades são marcantes nessas práticas sociais supracitadas.

Cabe, aqui, uma reflexão sobre a preocupação dos escritores fãs de ficção em promover e legitimar suas próprias práticas discursivas e sociais. Nesse ínterim, percebendo o direcionamento dos mediadores e administradores em alertar e incentivar o grupo de fãs de ficção para dedicarem-se a pesquisa e a criticidade. Em suma, os resultados do estudo exploratório corroboram para que há um novo paradigma de elaboração e compartilhamento de narrativas digitais frente à Cultura Participativa e a Cultura Digital na era da modernidade líquida. (BAUMAN, 2001; CLEMENTE, 2013; CLEMENTE; HAGUENAUER, 2014; MARCUSCHI, 2004).

\section{Discussão}

O advento da Cultura Participativa proporciona novos olhares aos estudos sobre Cultura Digital e aos novos estudos no campo da linguagem, isso porque, na modernidade com novas práticas discursivas e sociais há o surgimento de novos gêneros digitais e produção de gêneros discursivos em novas roupagens (MARCUSCHI, 2004). 
Para tal expansão dessas narrativas ficcionais, os fãs de ficção escrevem fanfics não para satisfazerem um processo de nostalgia após a leitura de uma obra original, todavia, para nutrir de novas aventuras, novas narrativas possíveis ao fandom a qual pertencem por afinidade.

Nessas relações de iniciar a elaboração de uma fanfiction, muitos fãs de ficção buscam interagir com outros pares do mesmo fandom nas redes sociais online. Assim, podem interagir, buscar inspiração em uma foto, numa história e, a partir dessa interação começarem a articular a produção de uma narrativa digital.

Há nessas práticas sociais online aspectos muito positivos em relação a compartilhar opiniões, respeitar a opinião alheia e de compartilhar informação. Percebemos aqui a fluidez dessa modernidade líquida nas/pelas relações e (inter) relações ao confrontarem com obras originais canônicas, clássicas e contemporâneas para defender a elaboração da fanfiction embasada em construtos ficcionais compatíveis com o que almeja o fandom de pertencimento.

Os estudos sobre as narrativas digitais e os novos gêneros digitais estão embasadas nos conceitos da Cultura da Convergência midiática abordados por Henry Jenkins (2009), narrativas multimodais de Janet Murray (2003), linguagem multissemiótica de Lúcia Santaella (2008).

$\mathrm{Na}$ perspectiva dos estudos sobre gêneros discursivos e dialogismos contextualizaremos as contribuições de Mikhail Bakhtin (2003) e no campo da Linguística Aplicada estaremos caminhando teoricamente na vertente (IN) disciplinar de Moita Lopes (2006) que dialoga para além das fronteiras disciplinares visando criar inteligibilidade sobre as relações discursivas e das práticas sociais mediadas pela linguagem e os recursos tecnológicos em espaços virtuais.

Por meio da leitura crítica dos construtos teóricos supracitados, retomaremos aos espaços virtuais da fase exploratória dessa investigação. O espaço virtual Nyah! Fanfiction é um site elaborado por um administrador que também se identifica como fã de ficção. As mudanças que as redes sociais e plataformas online agregaram às práticas sociais perpassam também a vida cultural, tanto pelo conteúdo imagético (SANTAELLA, 2008) quanto pelos novos formatos online que também estão inseridos aos suportes culturais físicos, o suporte impresso do livro e moldam novas formas de interagir com o conteúdo e a portabilidade dos mesmos. 
Ao trazer à baila os conceitos de modernidade líquida de Bauman (2001) e do gênero discursivo de Bakhtin (2003) podemos compreender como as narrativas digitais, enquanto gênero discursivo são gêneros secundários e fluídos, isso porque, são elaborados a partir de gêneros discursivos já existentes, contudo, em meio digital têm suas características alteradas, adaptadas para circularem nos espaços digitais, dessa forma, podem apresentar novas formas de apresentação, devido ao suporte de telas de computador, tabletes, smartphones, entre outros. Essas narrativas digitais são lidas na fluidez e na velocidade da modernidade líquida, em apenas alguns cliques são abertos e lidos, consumidos e, por diante compartilhamentos em links viajam pela Web 2.0.

Também à luz de Bauman (2001) que entende a atualidade imersa em uma vida de liquidez, perpassando desde o pensamento às práticas sociais, nesse fluxo há a fluidez da comunicação e das relações sociais online que inauguraram a partir dos anos dois mil novas formas de pensar, agir e mover-se em um espaço virtual ou virtualizado como os espaços virtuais da conectada Web 2.0 (CLEMENTE, 2013; MARCUSHI, 2004; JENKINS, 2009; MURRAY, 2003).

Os estudos sobre ciberespaço e a cibercultura têm investigado de forma muito profícua os percursos, as negociações, as condutas sociais dos sujeitos sociais online em espaço virtual, assim como, a Web 2.0 impulsionou a interação, sendo assim, os sujeitos sociais ao longo dessa evolução do ciberespaço e da Web 2.0 também foram adaptando as formas de pensar e agir em espaços virtuais, desta maneira, as práticas sociais e discursivas tornaram-se mais colaborativas e a informação mais acessível, ágil e compartilhável.

Nesse espaço da Web 2.0 os prosumers contribuem para que os gêneros discursivos existentes no papel passassem a ganhar novos formatos e visibilidade em espaços virtuais. A partir dessa integração e colaboração, assim, têm-se os fanfictions.

Esse gênero digital fanfiction avança de forma continua, mesmo diante ao atribulado debate sobre os direitos autorais e as atitudes autorais frente aos novos rumos do cenário ficcional, editorial nacional e/ou internacional e do advento da Cultura Digital. Nos registros no diário da pesquisadora registrou-se que o gênero digital fanfiction possui características pertinentes à produção textual de elaboração, processo editorial, normas de práticas discursiva e condutas de autoria negociáveis entre os sujeitos sociais participantes, esses são chamados de leitores fãs de ficção, escritores fãs de ficção e revisores fãs de ficção que leem, escrevem, revisam, comentam, refutam, 
interagem pelas redes sociais online e em espaços virtuais online. (JENKINS, 2009; MURRAY, 2003).

A Cibercultura elenca variadas narrativas, essas fluem em um não-lugar digital, emergem em um espaço efêmero. Para tal, o ciberespaço volátil, móvel e inconstante em fluxo de nós imbricados na rede tênue das conexões virtuais, tornam as estratégias narrativas, transmutadas em narrativas digitais, e portanto, gêneros discursivos que utilizam de novas roupagens para transitar nessas esferas modernas e sofisticadas, postas nos ambientes virtuais, não obstante, também plurais em apresentação narrativas (orais, textuais, visuais e acústicas) surgindo dessas interações a mixagem ou (re)mixagem dos gêneros emergentes contribuindo para práticas de letramentos digitais (MARCUSCHI, 2004; SANTAELLA, 2008; CLEMENTE, 2013).

A intensidade e as redes de informação das postagens na Internet são um crescente, junto a esse processo os comentários nos espaços virtuais são dados a serem analisados, buscamos em de Santaella (2008) o entendimento sobre evolução da comunicação que " não é algo engessado, pelo contrário marcam períodos históricos da comunicação humana e não se limitam a um período”. A Cultura Participativa surge no impulso dos consumidores a produzirem novas formas de informar e comunicar estabelecendo redes de informação. Segundo Jenkins (2009) a Cultura em que " fãs $e$ outros consumidores são convidados a participar ativamente da criação e da circulação de novos conteúdo" (JENKINS, 2009, p. 378) essa cultura surge como conceito e efeito para novas práticas sociais e discursivas, visto que, a linguagem enquanto processo de prática social também passa pela convergência e inovação, já que a audiência dos fãs de ficção nos espaços virtuais é materializado em comentários, sugestões, críticas e em novas narrativas ficcionais.

A comunicação midiática passou por mudanças significativas que segundo Jenkins (2009) a Convergência se refere “ a uma situação em que múltiplos sistemas de mídia coexistem e em que o conteúdo passa por eles fluidamente. " (JENKINS, 2009, p. 377), sendo assim, a linguagem midiática favoreceu a cooperação entre os mercados de cultura massiva. Desta maneira, o conteúdo e a informação circulam de forma mais rápida e proporcionam novos parâmetros de intervenção dos consumidores, consequentemente, novos hábitos de consumo e de comportamento dos consumidores em espaços virtuais foram afetados.

Os sujeitos sociais interagem com a comunicação midiática e a comunicação digital com muita desenvoltura e habilidade, já que com o advento da Web 2.0 e as 
mudanças de paradigma sobre interatividade esses sujeitos sociais também se modificaram, pois não adquirem o conteúdo como consumidores receptores passivos de informação, porém são prosumers conscientes de suas práticas de letramentos digitais. Eles podem reproduzir, mixar, interferir, refutar os dados de conteúdo com versatilidade e rapidez. Esse processo de narrativa são parte das práticas discursivas e sociais dos sujeitos sociais que segundo Murray (2003) " a narrativa é um dos nossos mecanismos cognitivos primários para a compreensão do mundo. É também um dos modos fundamentais pelos quais construídos comunidades, desde a tribo agrupada em volta da fogueira até a comunidade global [...]" (MURRAY, 2003, p.9).

Nessa perspectiva, as interações entre os sujeitos sociais online estão interligadas por meio das informações personalizadas de registro pessoal do cotidiano e da cultura digital. E, dentre as possibilidades de existir-evento - de acordo com Szundy (2014) no construto bakhtiniano o existir-evento está ligado aos atos responsáveis e responsivos dos sujeitos sócio-históricos. Enquanto esses sujeitos sociais em espaços virtuais na Cibercultura engendram um marco importante nas relações entre atos responsáveis e responsivos em continuidade sobre a elaboração do acervo da Cultura Digital. Haja vista, a maior interação e divulgação de conteúdos relacionados as obras ficcionais e revolução das práticas discursivas e sociais instantâneas e moventes em redes. (JENKINS, 2009; MURRAY, 2003; SANTAELLA, 2008).

Os gêneros discursivos secundários são fundamentais para registrar e captar as práticas discursivas do imaginário humano, desse modo, esses gêneros discursivos secundários podem encontrar no imaginário e na ficção novas formas de criar pontes de saberes com o mundo. O gênero discursivo (BAKHTIN, 2003) pode ser investigado pelas novas formas de entendimento na cultura digital, isso porque, muitos gêneros discursivos ganharam nova roupagem para o existir-evento nos suportes de tela, de aplicativos, de softwares nos espaços virtuais. Nessa vertente, segundo Clemente (2013, p. 65) o gênero digital fanfiction "seria uma construção da escrita digital em coautoria com as audiências de massa", sendo assim, no universo do fã não há limites estabelecidos previamente para buscar novos produtos ligados ao que gosta, como livros originais que são ampliados em vários capítulos pelos escritores/fã de ficção, ou até mesmo, filmes, séries ou outros formatos existentes também podem ser mote para novas sequências.

Os escritores fãs de ficção são usuários de plataformas online e usam apelidos (pen names) ou imagem ficcional (avatares), desta forma, são sujeitos sociais com 
identidades digitais e ficcionais distintas do mundo real, isso para serem aceitos no fandons (reinos de ficção) e interagirem com a divulgação de suas próprias fanfictions. Os escritores fãs de ficção buscam escrever fanfiction instigantes para além da obra ficcional que o fandom privilegia.

Essas narrativas bem trabalhadas em paridade com a essência da obra original, podem contagiar muitos seguidores - leitores fãs de ficção. Esses escritores fãs de ficção possuem a própria audiência, contudo, essa audiência tece comentários, atribuem curtidas e compartilhamentos e podem ter os capítulos escritos favoritados por muitos leitores fãs de ficção. Não obstante, há os leitores fãs de ficção mais críticos em comentários sobre os motes ficcionais utilizados e/ou personagens reelaborados na fanfiction.

A Linguística Aplicada (doravante LA) dialoga com teorias além das fronteiras do campo das ciências sociais e das humanidades, esse movimento, é denominado, segundo Moita Lopes (2006) como LA "mestiça, obviamente de natureza interdisciplinar/transdisciplinar" cabe ressaltar que a constituição dessas vertentes teórico-metodológicas impulsionam a LA na compreensão da importância de estudar à vida social em práticas situadas historicamente sobre as atividades humanas nas práticas discursivas, nas práticas sociais e culturais, como também, nas interações entre esses elementos.

E, partindo dessa concepção da LA sobre a interação pela linguagem, vislumbrase a concepção de dialogismo do Círculo de Bakhtin, em que apresenta o ser humano e sua consciência sendo constituída por um fluxo de comunicação verbal. Tendo em vista tais aspectos, essas interações nas práticas discursivas e sociais com uma postura crítica as atitudes responsivas estabeleceriam relações do $e u$ e do outro na esfera social. Essas relações de enunciados só adquirem vida no fluxo na comunicação verbal quando os sujeitos sociais estão situados de forma histórica, ideológica e social em práticas sociais e discursivas que impactam o existir-evento em espaços reais ou espaços virtuais.

Para o Círculo de Bakhtin as vozes sociais são imbuídas de capacidade crítica, reflexiva e responsiva. Sendo assim, todo dizer é orientado para uma resposta e todo enunciado espera uma resposta. Nesse contexto de investigação toda narrativa digital escrita para uma audiência como o fandom, na realidade é feita para ser consumida, lida, comentada e compartilhada pelos leitores fãs de ficção.

Nesse contexto, entendemos nessa investigação que esse construto se estende aos gêneros discursivos em espaços virtuais, visto que, a materialidade das vozes perpassa 
esses gêneros digitais emergentes, porque os atravessam e são alinhavados nas práticas de letramentos digitais dos fãs de ficção imersos na Cultura Participativa.

\section{Considerações Finais}

As novas interações na comunicação digital e as práticas sociais mediadas pelos recursos tecnológicos vêm colaborando para a construção de novos paradigmas sobre as relações sociais, todavia, os sujeitos sociais online participam e atuam de forma crítica e colaborativa nos espaços virtuais, portanto, as práticas de letramentos digitais são permanentes. Percebemos, ainda que, nesse existir-evento os fãs de ficção transitam pelos espaços virtuais com desenvoltura e contribuem para o advento da Cultura Participativa.

Dessas participações ativas os fãs de ficção passam a prosumer sob aquilo que consomem enquanto cultura, os espaços virtuais, também corroboram para serem espaços de reconfiguração de práticas de letramentos digitais. As narrativas digitais como o fanfiction colaboram para que as interações entre os pares sejam passíveis de investigação e análise, sobretudo, no campo da linguagem e das pesquisas sobre os sujeitos sociais situados historicamente no Ciberespaço e na Cibercultura.

A partir dos resultados empíricos do estudo exploratório cabe ressaltar alguns resultados a) a cultura participativa perpassa a comunicação midiática e a comunicação digital; b) o espaço virtual proporciona informação, comunicação e entretenimento e, abarcam narrativas digitais elaboradas por fãs de ficção; c) são diversas as opções de sites especializados em narrativas digitais, contudo, alguns sites são especializados apenas em fanfiction e outros sites de narrativas digitais só permitem narrativas digitais originais; d) As redes sociais online são espaços virtuais de encontro, debate de ideias e também de inspiração para novas fanfictions.

Em suma, nesta investigação, tentamos salientar a importância dos estudos sobre a Cultura de Participativa e as práticas de letramentos digitais por parte dos fãs de ficção nos espaços virtuais especializados no gênero digital fanfiction. 


\section{REFERÊNCIAS}

BAUMAN, Z. Modernidade líquida. Rio de Janeiro: Zahar, 2001.

BAKHTIN, M. Estética da Criação Verbal. 4.ed. São Paulo: Martins Fontes, 2003.

CLEMENTE, B. J. B. O uso do fanfiction nas aulas de produção textual no ensino médio. Dissertação (Mestrado). Universidade Federal do Rio de Janeiro - UFRJ, 147f., 2013.

CLEMENTE, B. J. B;. HAGUENAUER. C.J. Aplicação do Fanfiction nas Aulas de Produção Textual no Ensino Médio. Revista Hipertexto, v. 4, n. 1, Janeiro/Junho 2014, pp.56-78. ISSN: 2236-515X.

HINE, C. Virtual Ethnography. Editora SAGE Publications, 2000.

JENKINS, H. Cultura da convergência: a colisão entre os velhos e novos meios de comunicação. Trad. S. Alexandria. São Paulo: Aleph, 2009.

MARCUSCHI, L.; MARCUSCHI, L. A. Gêneros virtuais emergentes no contexto da tecnologia digital. In: MARCUSCHI \& XAVIER, Antônio Carlos dos Santos (orgs.). Hipertexto e gêneros digitais: novas formas de construção do sentido. Rio de Janeiro: Lucerna, 2004.

MOITA LOPES, L. P. (Org.). Por uma linguística aplicada INdisciplinar. São Paulo: Parábola, 2006.

MURRAY, J. H. Hamlet no Holodeck: o futuro da narrativa no ciberespaço. Trad. Daher; Cuzziol. São Paulo: Itaú Cultural: Unesp, 2003.

SANTAELLA, L. O novo estatuto do texto nos ambientes de hipermídia. In: SIGNORINI, Inês. (Org.) [Re] Discutir texto, gênero e discurso. São Paulo: Parábola, 2008.

SZUNDY, P. T. C. Educação como ato responsável: a formação de professores de linguagens à luz da filosofia da linguagem do Círculo de Bakhtin. Trab. linguist. apl.[online]. 2014, vol.53, n.1, pp.13-32. ISSN 2175-764X. Disponível em: <http://dx.doi.org/10.1590/s0103-18132014000100002>. [1]

VARGAS, M. L. B. Do fã consumidor ao fã navegador: o fenômeno fanfiction. $210 \mathrm{f}$. Dissertação (Mestrado em Letras), Instituto de Filosofia e Ciências Humanas, Universidade de Passo Fundo, Passo Fundo, 2005.

VARGAS, M. L. B. Slash: a fan fiction homoerótica no fandom potteriano brasileiro. 182f. Tese (Doutorado em Letras). Porto Alegre: PUC, 2011. 


\section{Como referenciar este artigo}

CLEMENTE, Bianca Jussara Borges. A cultura participativa e as práticas de letramentos de fãs de ficção: uma investigação empírica. Revista Ibero-Americana de Estudos em Educação, Araraquara/SP, v. 11, n. esp. 3, p.1710-1726, 2016. Disponível em: 〈http://dx.doi.org/10.21723/riaee.v11.n.esp3.9069>. E-ISSN: 1982-5587.

Submetido em: agosto/2016

Aprovado em: novembro/2016 